\title{
Planar MIMO Antenna with Slits for WBAN Applications
}

\author{
Do-Gu Kang, Jinpil Tak, and Jaehoon Choi \\ Department of Electronics and Communications Engineering, Hanyang University, 222 Wangsimni-ro, Seongdong-gu, \\ Seoul 133-791, Republic of Korea \\ Correspondence should be addressed to Jaehoon Choi; choijh@hanyang.ac.kr
}

Received 30 April 2014; Revised 25 June 2014; Accepted 2 July 2014; Published 13 July 2014

Academic Editor: Yingsong Li

Copyright (C) 2014 Do-Gu Kang et al. This is an open access article distributed under the Creative Commons Attribution License, which permits unrestricted use, distribution, and reproduction in any medium, provided the original work is properly cited.

A planar MIMO antenna with slits for WBAN applications is proposed. The antenna consists of two PIFAs, ground pads, and two slits. By adding ground pads, the antenna size is reduced with improved impedance matching. Through two slits in a ground plane, the isolation characteristic is improved and the resonant frequency can be controlled. To analyze the antenna performance on a human body, the proposed antenna on a human equivalent flat phantom is investigated through simulations. Regardless of the existence of the phantom, the antenna operates in $2.4 \mathrm{GHz}$ ISM band with the isolation higher than $18 \mathrm{~dB}$.

\section{Introduction}

Recently, wireless body area network (WBAN) systems for medical devices, police and military agencies, sports training, entertainment, and wearable computing have received great attention in conjunction with the rapid development of wireless communication technology $[1,2]$. The antennas for WBAN system should satisfy certain requirements such as small size, low profile, low human body effects, and low specific absorption rate (SAR) [3]. Since the antennas for WBAN system are located on or in the human body, the performance of the antenna is affected by the human body's high dielectric constant and conductivity at the microwave frequency band. Therefore, the gain and radiation efficiency of the antenna can deteriorate [4-7].

A lot of research for the on-body communication channel of WBAN system in the industrial scientific medical (ISM) band has been conducted [8-10]. In on-body communication, a multipath fading occurs due to reflections from the surrounding environment and the body parts, large relative movement of the body parts, shadowing, and scattering from the moving of the body and the surrounding environment [8]. The multipath fading distorts communication signals and reduces the efficiency of WBAN system [11]. Since a diversity technique forces signals to be independently processed, stable communication performance of an antenna system can be achieved in multipath fading environment. Multiple-input and multiple-output (MIMO) antennas have received much attention as one of promising diversity techniques. A high isolation characteristic is essential for MIMO antenna system in order to achieve independency of multiple signals [12].

In the paper, a planar MIMO antenna with slits for on-body WBAN applications in $2.4 \mathrm{GHz}$ ISM band (2.4 $2.485 \mathrm{GHz}$ ) is proposed. A planar inverted-F antenna (PIFA) operating with a resonant length of $\lambda / 4$ is used to achieve compact size [13]. Ground pads are added to reduce the size of the antenna with improved impedance matching. By using two slits in a ground plane, the isolation characteristic increases over $18 \mathrm{~dB}$ in $2.4 \mathrm{GHz}$ ISM band. The performance of the proposed antenna on the human equivalent flat phantom such as $S$-parameter characteristics, radiation characteristics, SAR, and an envelope correlation coefficient (ECC) is analyzed.

\section{Antenna Geometry}

Figure 1 shows the geometry of the proposed antenna. The antenna consists of two identical PIFAs, two identical ground pads, and two identical slits. The proposed planar antenna is designed on a FR4 substrate $\left(\varepsilon_{r}=4.4\right)$ with a $1 \mathrm{~mm}$ thickness. The total size of the substrate is $40 \times 40 \mathrm{~mm}^{2}$. 


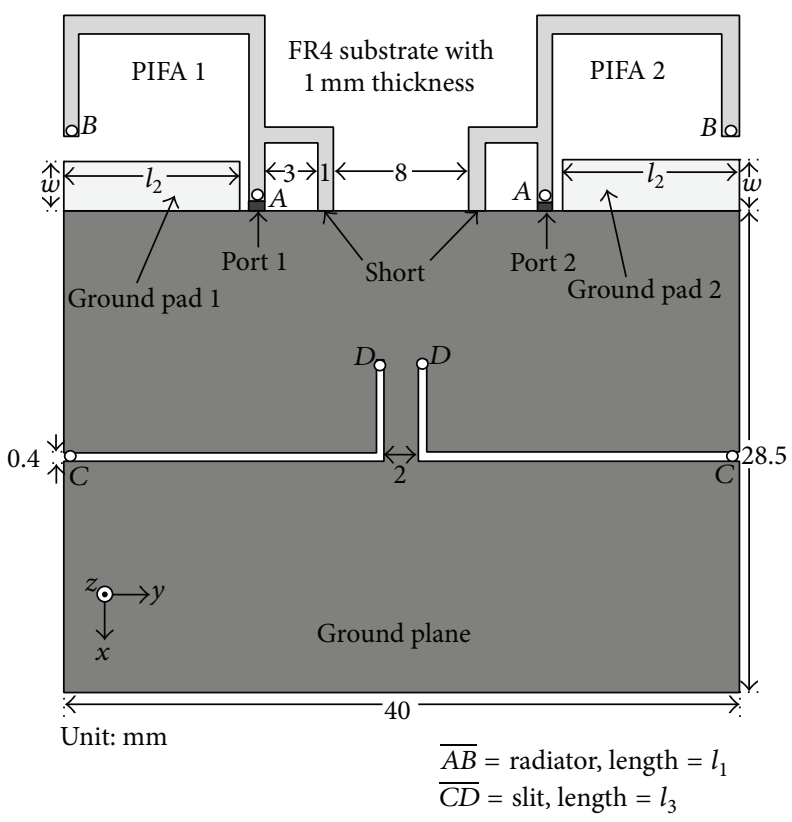

FigURE 1: Geometry of the proposed antenna.

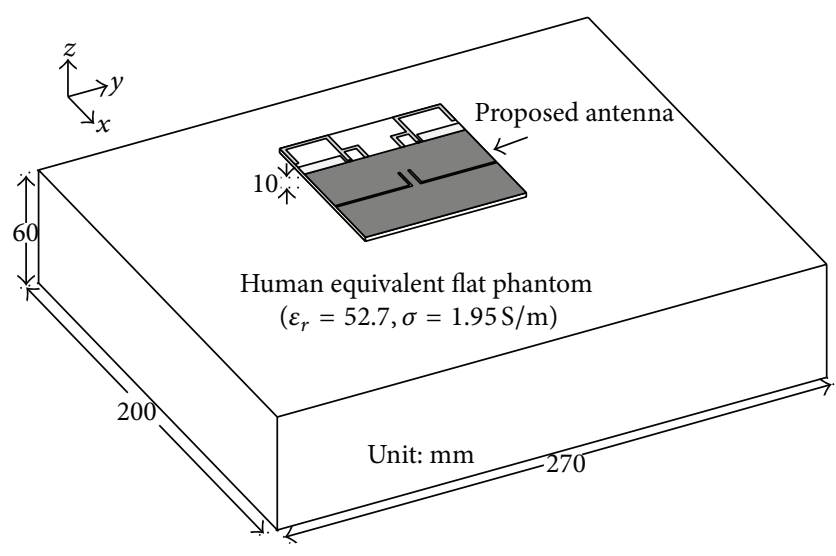

FIGURE 2: Proposed antenna on the human equivalent flat phantom.

PIFAs have a dimension of $11.5 \times 16 \times 1 \mathrm{~mm}^{3}$. A distance between the two PIFAs is $8 \mathrm{~mm}$ and $l_{1}$ denotes the length of the radiator of PIFAs. Addition of ground pads at a ground plane increases the electrical length and bandwidth of PIFAs without changing the size of PIFAs. $l_{2}$ and $w$, respectively, denote the length and the width of the ground pads. Although an isolator does not exist between the two PIFAs, the isolation characteristic is improved by adding two slits with the length of $l_{3}$ in the ground plane.

Figure 2 shows the proposed antenna on the human equivalent flat phantom. The dimension of the human equivalent flat phantom is $200 \times 270 \times 60 \mathrm{~mm}^{3}$. The proposed antenna for possible applications (portable devices such as Bluetooth headset and wearable smart watch) has the maximum allowed separation distance of $10 \mathrm{~mm}$ from the phantom in order to provide the clearance of cover assembly [4]. To account for this situation, the separation distance

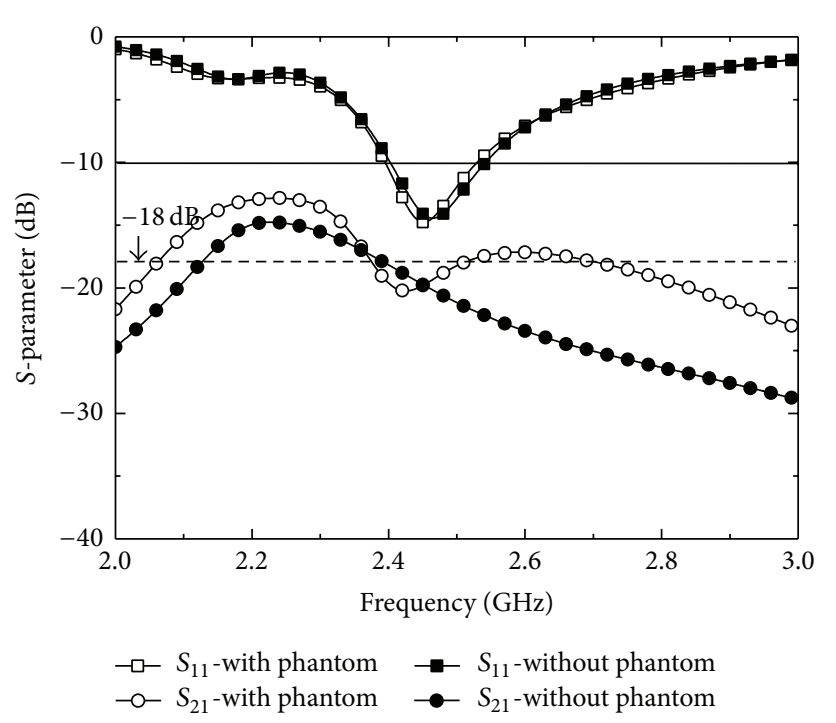

FIGURE 3: Simulated $S$-parameter results for the proposed antenna with phantom and without phantom.

between the antenna and the phantom is chosen as $10 \mathrm{~mm}$. In order to analyze the antenna performance on a human body, simulations were conducted using the human equivalent flat phantom having the equivalent electrical properties $\left(\varepsilon_{r}=\right.$ 52.7 and $\sigma=1.95 \mathrm{~S} / \mathrm{m}$ ) of human tissue [14]. The simulation results were obtained using HFSS based on the finite-element method [15].

\section{Simulated Results}

Figure 3 shows the simulated $S$-parameter results for the proposed antenna with and without the phantom. The design 


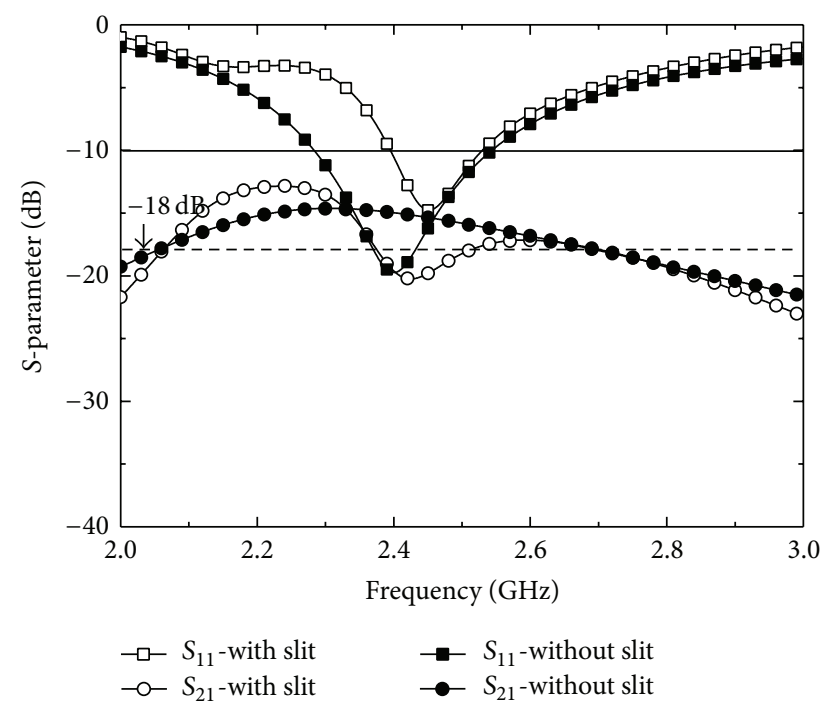

FIGURE 4: Simulated S-parameter results for the proposed antenna on the phantom with slit and without slit.

parameters for the proposed antenna are set to $l_{1}=28 \mathrm{~mm}$, $l_{2}=10.5 \mathrm{~mm}, w=3 \mathrm{~mm}$, and $l_{3}=24 \mathrm{~mm}$. Regardless of the existence of the phantom, $S_{11}$ is maintained below $-10 \mathrm{~dB}$ and the isolation characteristic is higher than $18 \mathrm{~dB}$ over the $2.4 \mathrm{GHz}$ ISM band $(2.4 \sim 2.485 \mathrm{GHz})$.

Figure 4 shows the simulated $S$-parameter results for the proposed antenna on the phantom with slit and without slit. By adding a slit at the ground plane, the isolation at $2.44 \mathrm{GHz}$ is improved from $15 \mathrm{~dB}$ to $20 \mathrm{~dB}$. The isolation characteristic over the entire $2.4 \mathrm{GHz}$ ISM band is higher than $18 \mathrm{~dB}$.

Figure 5 shows the simulated surface current distributions for the proposed antenna at $2.44 \mathrm{GHz}$. The slit operates at the electrical length of $\lambda / 4$. Because the minimum current of the slit implies high impedance by $\lambda / 4$ slit, the slit blocks current flowing from PIFA 1 to PIFA 2 through the ground plane $[16,17]$. For the antenna without slit, when PIFA 1 is excited by port 1, a strong current excites on PIFA 2 as shown in Figure 5(a). For the antenna with slit, a weak current excites on PIFA 2 as depicted in Figure 5(b).

Figure 6 shows the simulated $S$-parameter results for various values of length $l_{1}$. Other parameters, excluding $l_{1}$, are the same as described above. A resonance frequency is formed by the length of radiator $(\lambda / 4)$. As $l_{1}$ increases, the radiator approaches the ground pad. Therefore, the resonance frequency decreases with a deteriorated impedance matching. However, the isolation characteristic is maintained above $18 \mathrm{~dB}$. Because the distance between the PIFA and the slit is far enough as shown in Figure 5(b), the change of the radiator's length hardly affects the isolation characteristic. When $l_{1}$ is $28 \mathrm{~mm}, 10 \mathrm{~dB}$ return loss bandwidth of the antenna fully covers $2.4 \mathrm{GHz}$ ISM band.

Figure 7 shows the simulated $S$-parameter results for various values of length $l_{2}$. As $l_{2}$ increases, the resonance frequency decreases because the coupling between the ground pad and the part of PIFA near feeding port becomes stronger in Figure 5(b). The isolation characteristic is retained above

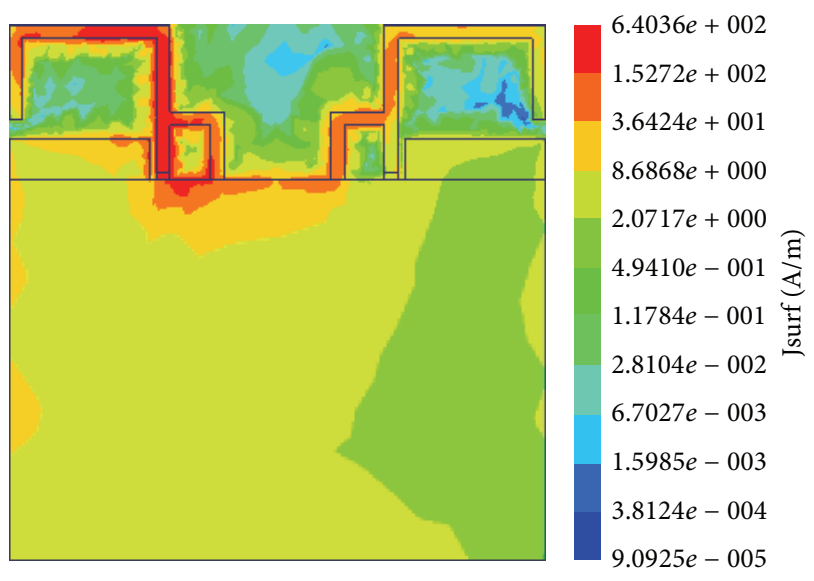

(a)

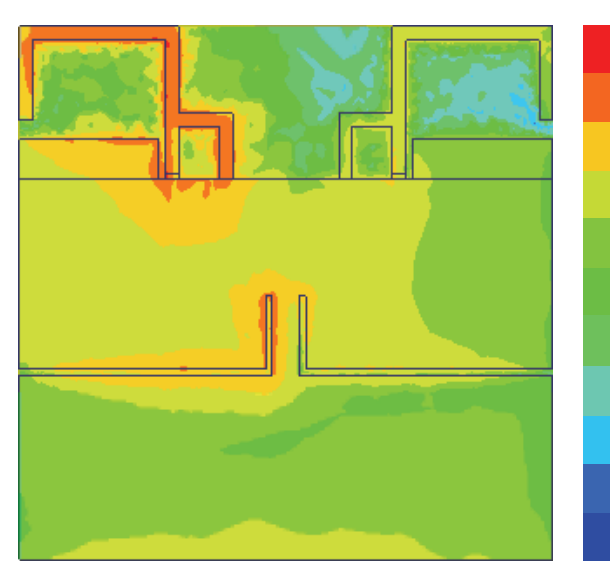

$6.4036 e+002$

$1.5272 e+002$

$3.6424 e+001$

$8.6868 e+000$

$2.0717 e+000$

$4.9410 e-001$

$1.1784 e-001$

$2.8104 e-002$

$6.7027 e-003$

$1.5985 e-003$

$3.8124 e-004$

$9.0925 e-005$

(b)

FIGURE 5: Simulated surface current distributions for the proposed antenna at $2.44 \mathrm{GHz}$ (port 1: on, port 2: off) (a) without slit and (b) with slit.

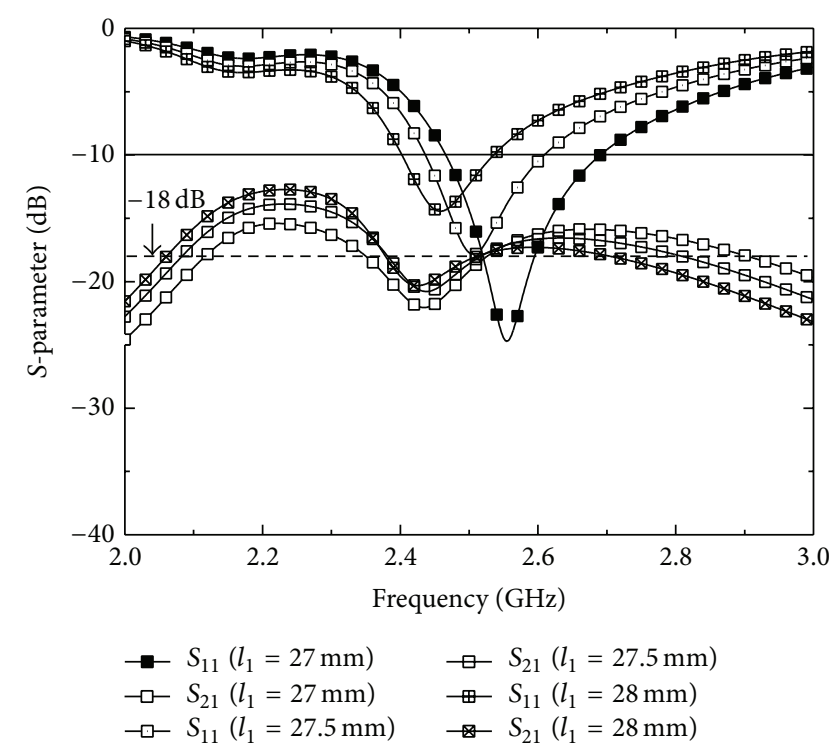

FIGURE 6: Simulated $S$-parameter results for various values of length $l_{1}$. 


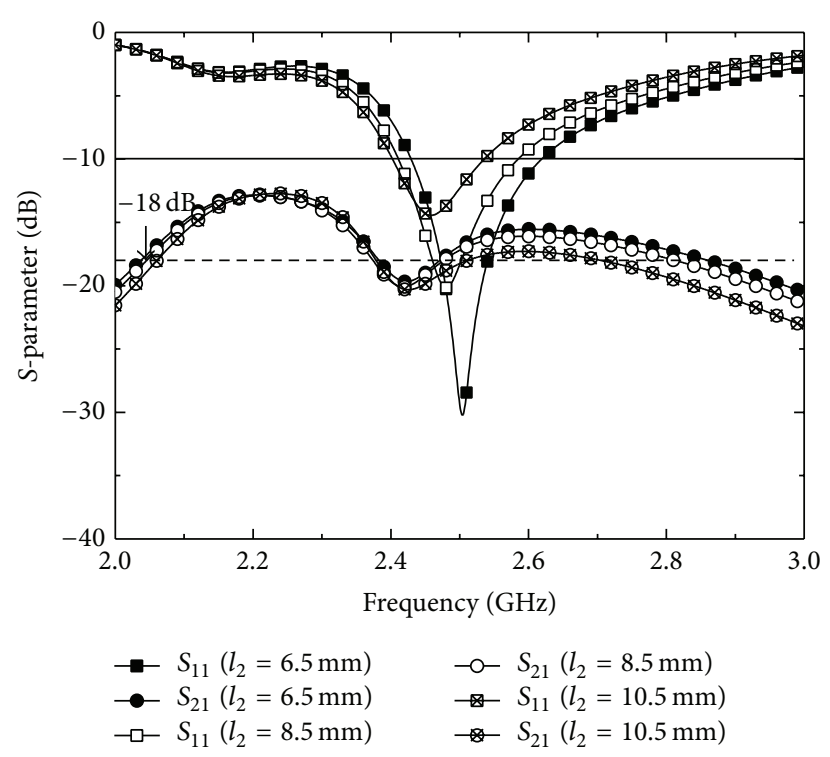

FIGURE 7: Simulated $S$-parameter results for various values of length $l_{2}$.

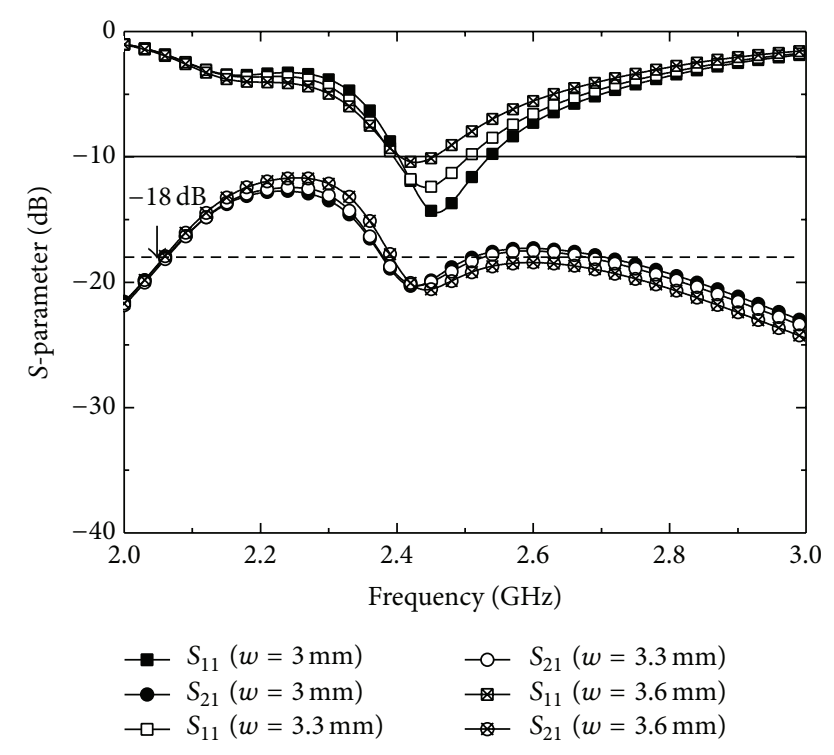

FIGURE 8: Simulated $S$-parameter results for various values of width $w$.

$18 \mathrm{~dB}$. Because $l_{2}$ is the length of the ground pad, the addition of ground pad contributes to the size reduction of the PIFA. When $l_{2}$ is $10.5 \mathrm{~mm}$, the best isolation performance in $2.4 \mathrm{GHz}$ ISM band is achieved.

Figure 8 shows the simulated $S$-parameter results for various values of width $w$. As $w$ decreases, the resonance frequency increases because the coupling between the ground pad and the tip of PIFA becomes weaker in Figure 5(b). The $10 \mathrm{~dB}$ return loss bandwidth increases with an improved impedance matching. The isolation characteristic remains nearly constant above $18 \mathrm{~dB}$ regardless of the change in $w$. To cover $2.4 \mathrm{GHz}$ ISM band, $w$ is chosen as $3 \mathrm{~mm}$.

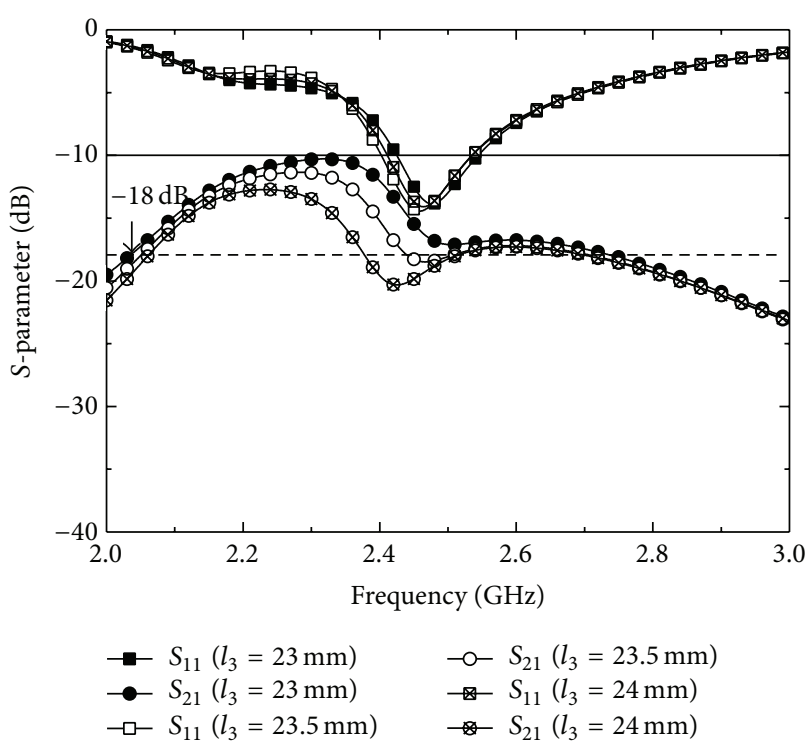

FIGURE 9: Simulated $S$-parameter results for various values of length $l_{3}$.

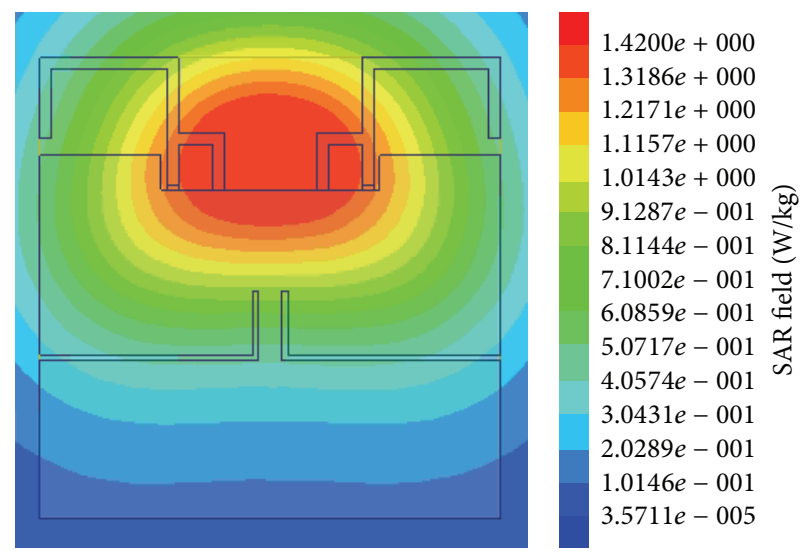

FIGURE 10: Simulated SAR distribution of the proposed antenna on the phantom at $2.44 \mathrm{GHz}$ (input power: $100 \mathrm{~mW}$ ).

Figure 9 shows the simulated $S$-parameter results for various values of length $l_{3}$. As $l_{3}$ increases, the isolation characteristic is improved, while the $S_{11}$ characteristic is retained. Because $l_{3}$ is the length of the slit, the change of $l_{3}$ mainly affects the isolation characteristic. When $l_{3}$ is chosen as $24 \mathrm{~mm}$, the isolation characteristic is higher than $18 \mathrm{~dB}$ in $2.4 \mathrm{GHz}$ ISM band.

Figure 10 shows the simulated SAR distribution of the proposed antenna on the phantom at $2.44 \mathrm{GHz}$. According to the Federal Communications Commission (FCC), the SAR values for a partial body should be below $1.6 \mathrm{~W} / \mathrm{kg}$ over a volume of $1 \mathrm{~g}$ of tissue [18]. When the maximum input power is $100 \mathrm{~mW}$, the SAR of the proposed antenna is $1.42 \mathrm{~W} / \mathrm{kg}$ which satisfies the FCC SAR limitation of $1.6 \mathrm{~W} / \mathrm{kg}$. Therefore, the proposed antenna can be used for a low power wireless terminal operating below $100 \mathrm{~mW}$ such as Bluetooth system [19]. 


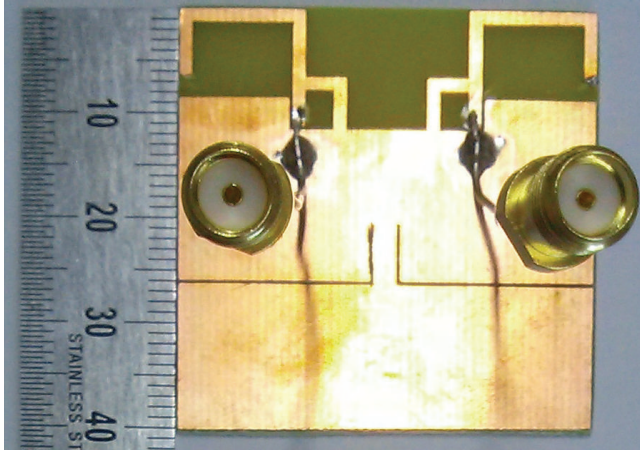

(a)

FIGURE 11: Fabricated antenna and phantom for measurement setup. measurement setup.

TABLe 1: Simulated total efficiency at $2.44 \mathrm{GHz}$.

\begin{tabular}{lcc}
\hline $2.44 \mathrm{GHz}$ & With slits & Without slits \\
\hline Total efficiency (\%) & $\mathbf{4 0 . 3 5}$ & $\mathbf{3 8 . 2 6}$ \\
\hline
\end{tabular}

Table 1 shows the simulated total efficiency at $2.44 \mathrm{GHz}$. The total efficiency of the proposed antenna is higher than that of the antenna without the slits due to the improvement of isolation between the two antenna elements by inserting the slits.

\section{Measured Results}

Figure 11 shows the fabricated antenna and phantom for measurement setup. The measured electrical properties of the fabricated human equivalent semisolid flat phantom are $\varepsilon_{r}=$ 52.7 and $\sigma=1.95 \mathrm{~S} / \mathrm{m}$ [20]. The human equivalent semisolid flat phantom is used to measure the antenna performance.

Figure 12 shows the simulated and measured $S$-parameter results for the proposed antenna. The simulated results are virtually identical to the measured results. The discrepancy between the simulated and the measured results may have been due to a manufacturing error (long coaxial feed cable) of the fabricated antenna [21]. The proposed antenna has the $10 \mathrm{~dB}$ return loss bandwidth of $210 \mathrm{MHz}(2.34 \sim 2.55 \mathrm{GHz})$. This is wide enough to fully cover $2.4 \mathrm{GHz}$ ISM band. The isolation characteristic is higher than $20 \mathrm{~dB}$ over $2.4 \mathrm{GHz}$ ISM band.

Figure 13 shows the simulated and measured radiation patterns of the proposed antenna at $2.44 \mathrm{GHz}$. The measured radiation patterns agree well with the simulated ones. The radiation patterns of the PIFA 1 and PIFA 2 are similar to each other. In Figure 13(a), nearly omnidirectional radiation patterns are observed. In Figure 13(b), radiation patterns directed toward the outside of phantom are observed. Table 2 shows the measured peak gain and radiation efficiency of the proposed antenna at $2.44 \mathrm{GHz}$. The peak gain is $1.61 \mathrm{dBi}$ for the PIFA 1 and $1.6 \mathrm{dBi}$ for the PIFA 2.

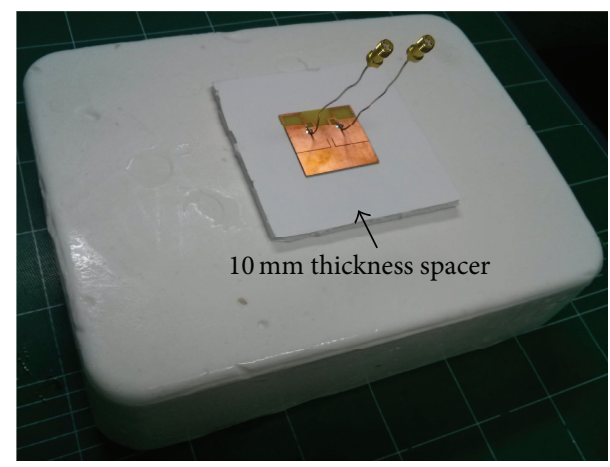

(b)

(a) Fabricated antenna and (b) the antenna on the phantom for

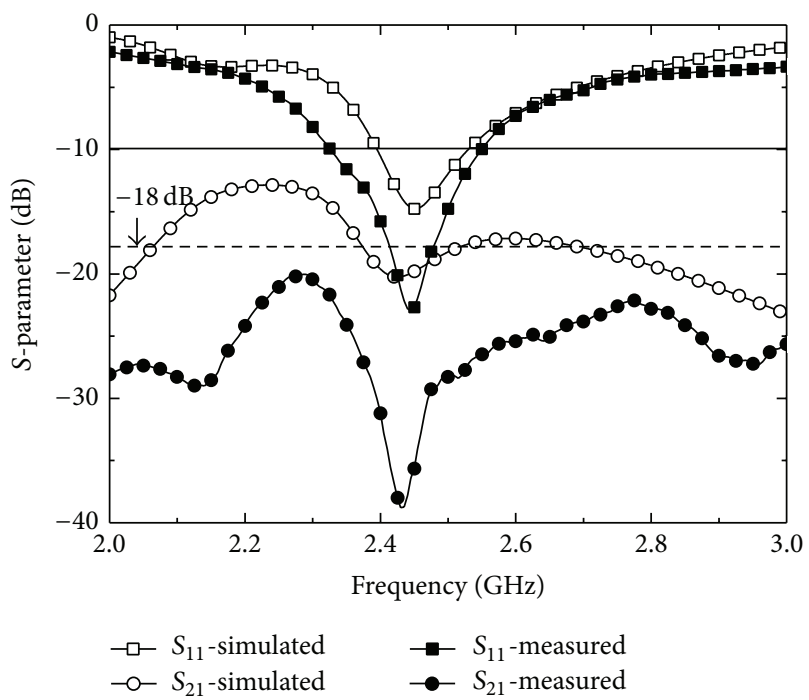

FIGURE 12: Simulated and measured $S$-parameter results for the proposed antenna.

TABLE 2: Measured peak gain and radiation efficiency.

\begin{tabular}{lcc}
\hline $2.44 \mathrm{GHz}$ & PIFA 1 & PIFA 2 \\
\hline Peak gain $(\mathrm{dBi})$ & 1.61 & 1.6 \\
Efficiency $(\%)$ & 24.97 & 24.29 \\
\hline
\end{tabular}

The diversity performance of a MIMO antenna could be evaluated by the envelope correlation coefficient (ECC). The ECC should be calculated from 3D radiation patterns [22]. Figure 14 shows the calculated ECC from simulated and measured radiation patterns of the proposed antenna. The simulated ECC agrees well with the measured ECC. The ECC values are maintained below 0.5 over $2.4 \mathrm{GHz}$ ISM band. The simulated ECC of the proposed antenna is lower than that of the antenna without slits due to the improvement of isolation between the two antenna elements by inserting the slits. 


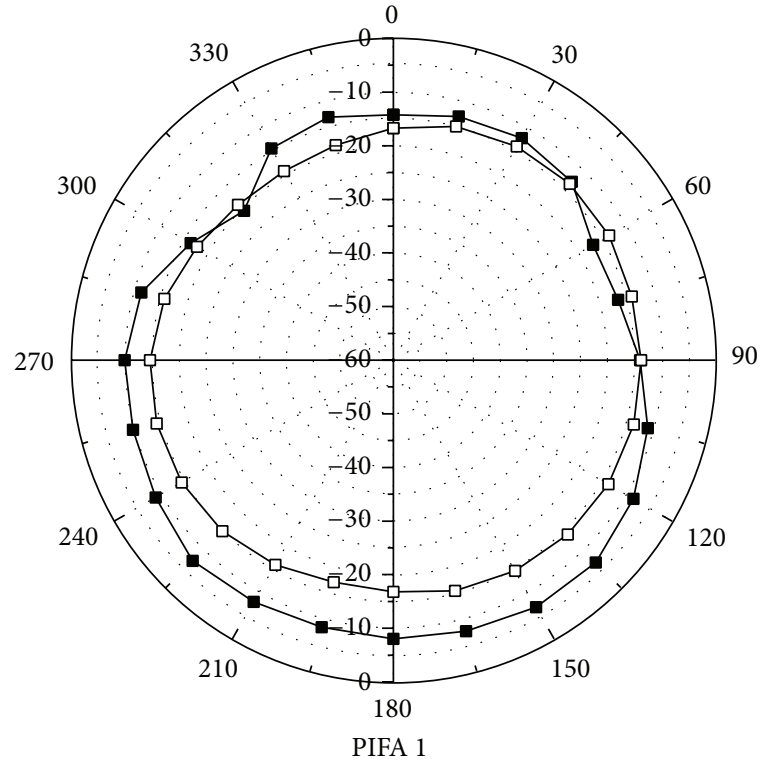

$\neg-$ Simulation

$\rightarrow$ - Measurement

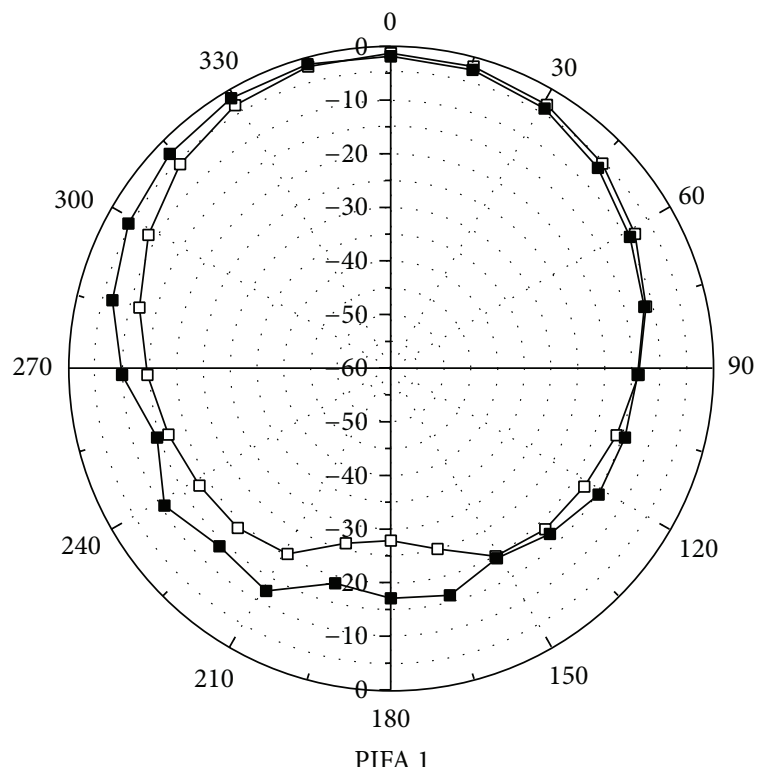

$\neg-$ Simulation

$\rightarrow$ - Measurement

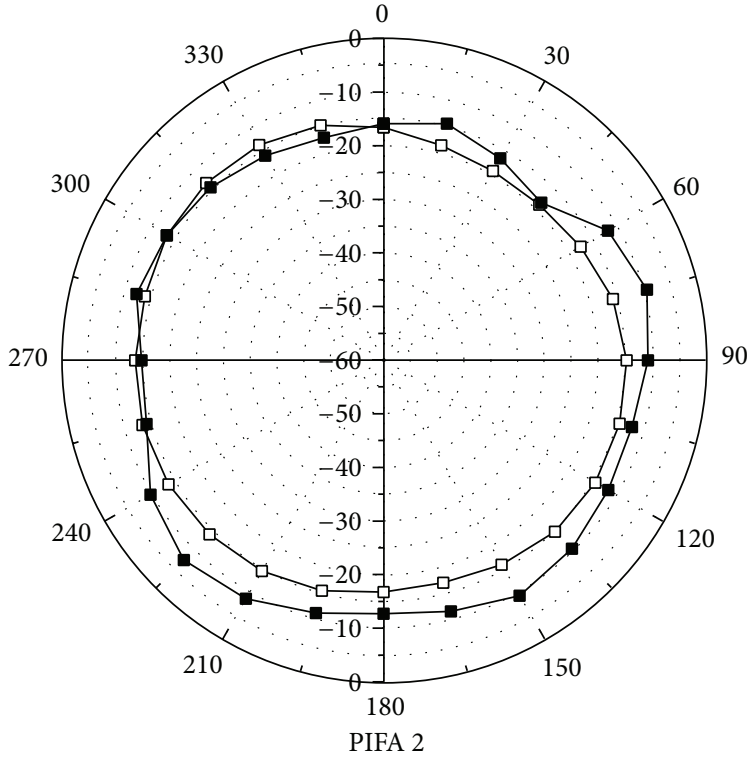

$\neg-$ Simulation

- Measurement

(a)

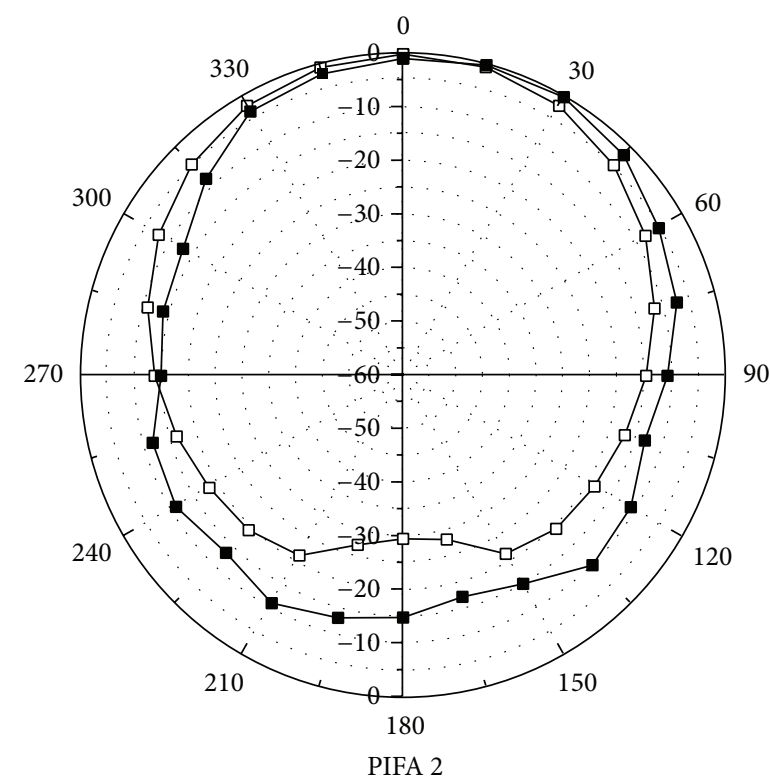

$\neg-$ Simulation

$\rightarrow$ - Measurement

)

FIGURE 13: Simulated and measured radiation patterns of the proposed antenna at $2.44 \mathrm{GHz}$ (a) $x y$ plane and (b) $y z$ plane.

\section{Conclusion}

In this paper, the planar MIMO antenna with slits in $2.4 \mathrm{GHz}$ ISM band for WBAN applications is proposed. The $10 \mathrm{~dB}$ return loss bandwidth of the antenna on the human equivalent flat phantom is wide enough to cover $2.45 \mathrm{GHz}$ ISM band. The addition of ground pads contributes to the size reduction and the improvement of the impedance matching of the PIFA.
The isolation characteristic is improved by adding two slits. The isolation is higher than $18 \mathrm{~dB}$ over the ISM band. The resonant frequency can be controlled by the PIFA, the ground pad, and the slit. The performance of proposed antenna is insensitive to the existence of the phantom. Consequently, the above advantages make the proposed antenna a good candidate for WBAN applications. 


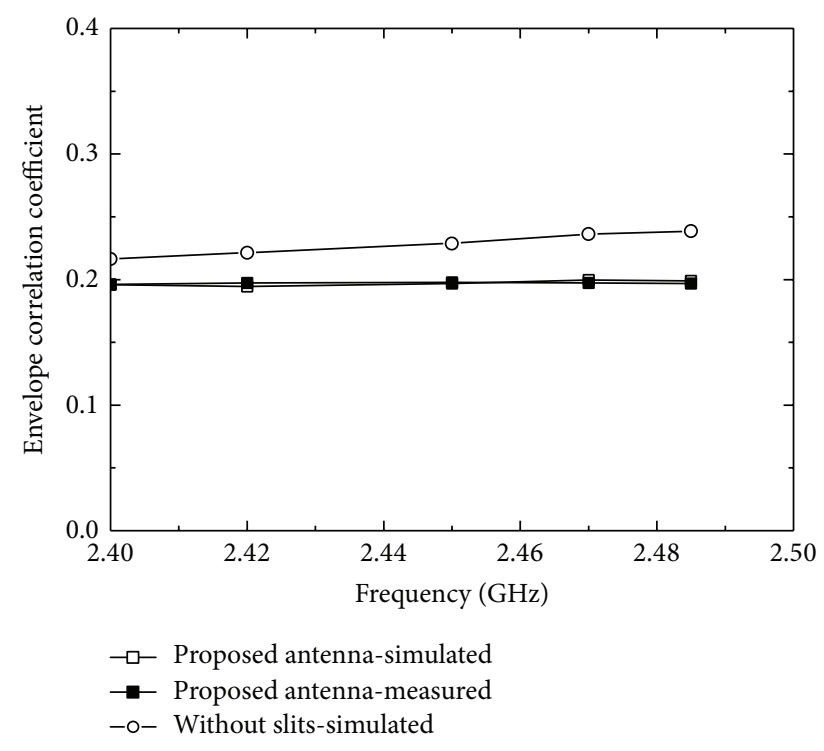

FIGURE 14: Simulated and measured envelope correlation coefficient of the proposed antenna and the antenna without slits.

\section{Conflict of Interests}

The authors declare that there is no conflict of interests regarding the publication of this paper.

\section{Acknowledgment}

This research was supported by the MSIP (Ministry of Science, ICT \& Future Planning), Republic of Korea, under the ITRC (Information Technology Research Center) support program (NIPA-2014-H0301-14-1017) supervised by the NIPA (National IT Industry Promotion Agency).

\section{References}

[1] T. Zasowski, F. Althaus, M. Stager, A. Wittneben, and G. Troster, "UWB for noninvasive wireless body area networks: channel measurements and results," in Proceedings of the IEEE Conference on Ultra Wideband Systems and Technologies, pp. 285-289, 2003.

[2] P. S. Hall and Y. Hao, "Introduction to body-centric wireless communications," in Antennas and Propagation for BodyCentric Wireless Communications, chapter 1, Artech House, Norwood, Mass, USA, 2006.

[3] N. Haga, K. Saito, M. Takahashi, and K. Ito, "Characteristics of cavity slot antenna for body-area networks," IEEE Transactions on Antennas and Propagation, vol. 57, no. 4, pp. 837-843, 2009.

[4] M. Ur Rehman, Y. Gao, Z. Wang et al., "Investigation of onbody bluetooth transmission," IET Microwaves, Antennas and Propagation, vol. 4, no. 7, pp. 871-880, 2010.

[5] C. Deng, X. Liu, Z. Zhang, and M. M. Tentzeris, "A miniascapelike triple-band monopole antenna for WBAN applications," IEEE Antennas and Wireless Propagation Letters, vol. 11, pp. 1330-1333, 2012.

[6] Z. N. Chen, A. Cai, T. S. P. See, X. Qing, and M. Y. W. Chia, "Small planar UWB antennas in proximity of the human head,"
IEEE Transactions on Microwave Theory and Techniques, vol. 54, no. 4, pp. 1846-1856, 2006.

[7] P. S. Hall, Y. Hao, Y. I. Nechayev et al., "Antennas and propagation for on-body communication systems," IEEE Antennas and Propagation Magazine, vol. 49, no. 3, pp. 41-58, 2007.

[8] A. A. Serra, P. Nepa, G. Manara, and P. S. Hall, "Diversity for body area networks," in Proceedings of the 29th URSI General Assembly, pp. 1-4, Chicago, Ill, USA, August 2008.

[9] L. Akhoondzadeh-Asl, I. Khan, and P. S. Hall, "Polarisation diversity performance for on-body communication applications," IET Microwaves, Antennas and Propagation, vol. 5, no. 2, pp. 232-236, 2011.

[10] T. Aoyagi, M. Kim, J. Takada, K. Hamaguchi, and R. Kohno, "Numerical simulations for wearable BAN propagation channel during various human movements," IEICE Transactions on Communications, vol. E94-B, no. 9, pp. 2496-2500, 2011.

[11] S. L. Cotton and W. G. Scanlon, "A statistical analysis of indoor multipath fading for a narrowband wireless body area network," in Proceedings of the IEEE 17th International Symposium on Personal, Indoor and Mobile Radio Communications (PIMRC '06), pp. 1-5, Helsinki, Finland, September 2006.

[12] S. Zhang, B. K. Lau, A. Sunesson, and S. He, "Closely-packed UWB MIMO/diversity antenna with different patterns and polarizations for USB dongle applications," IEEE Transactions on Antennas and Propagation, vol. 60, no. 9, pp. 4372-4380, 2012.

[13] Y. Guo, M. Y. W. Chia, and Z. N. Chen, "Miniature built-in multiband antennas for mobile handsets," IEEE Transactions on Antennas and Propagation, vol. 52, no. 8, pp. 1936-1944, 2004.

[14] D. L. Means and W. Kwok, "Evaluating compliance with FCC guidelines for human exposure to radiofrequency electromagnetic fields," Supplement C (Edition 01-01) to OET Bulletin 65 (Edition 97-01), Federal Communications Commission Office of Engineering \& Technology, 2001.

[15] "Ansys High Frequency Structure Simulator (HFSS), Version 14," Ansys Corporation.

[16] M. Ayatollahi, Q. Rao, and D. Wang, "A compact, high isolation and wide bandwidth antenna array for long term evolution wireless devices," IEEE Transactions on Antennas and Propagation, vol. 60, no. 10, pp. 4960-4963, 2012.

[17] J. Lim, Z. Jin, C. Song, and T. Yun, "Simultaneous frequency and isolation reconfigurable MIMO PIFA using PIN diodes," IEEE Transactions on Antennas and Propagation, vol. 60, no. 12, pp. 5939-5946, 2012.

[18] "IEEE standard for safety levels with respect to human exposure to radio frequency electromagnetic fields, $3 \mathrm{KHz}$ to $300 \mathrm{GHz}$," IEEE Standard C95.1.1999, 1999.

[19] M. Patel and J. Wang, "Applications, challenges, and prospective in emerging body area networking technologies," IEEE Wireless Communications, vol. 17, no. 1, pp. 80-88, 2010.

[20] S. Lee, W. Seo, K. Kwon, and J. Choi, "The study on implementation of a semi-solid flat phantom with equivalent electrical properties to whole human body at MICS and ISM band," The Journal of Korea Electromagnetic Engineering Society, vol. 23, no. 1, pp. 101-107, 2012.

[21] Y. Okano, "A simple shape broadband planar antenna adaptable to RFID-tag," IEEE Transactions on Antennas and Propagation, vol. 54, no. 6, pp. 1885-1888, 2006.

[22] J. Li, Q. Chu, and T. Huang, "A compact wideband MIMO antenna with two novel bent slits," IEEE Transactions on Antennas and Propagation, vol. 60, no. 2, pp. 482-489, 2012. 

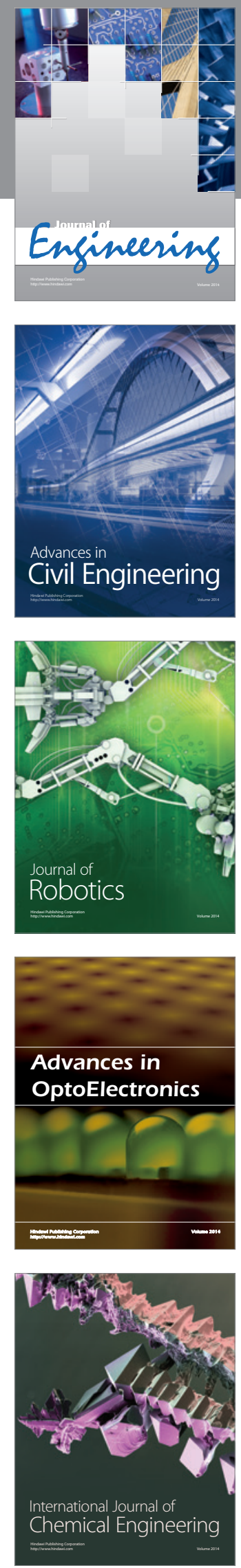

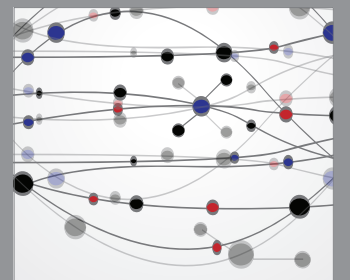

The Scientific World Journal
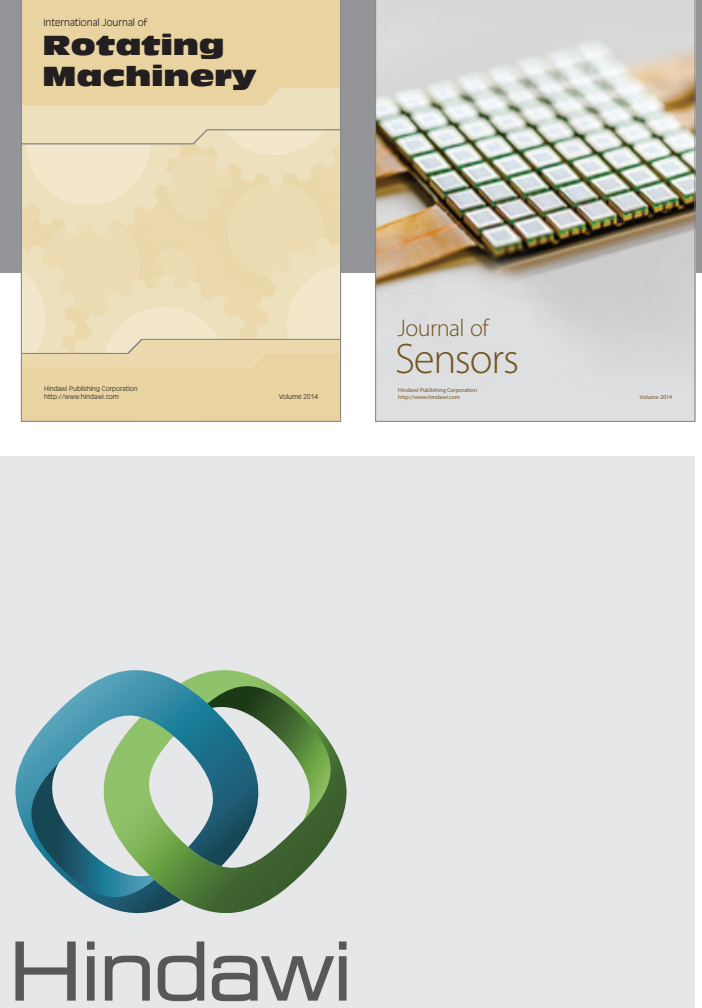

Submit your manuscripts at http://www.hindawi.com
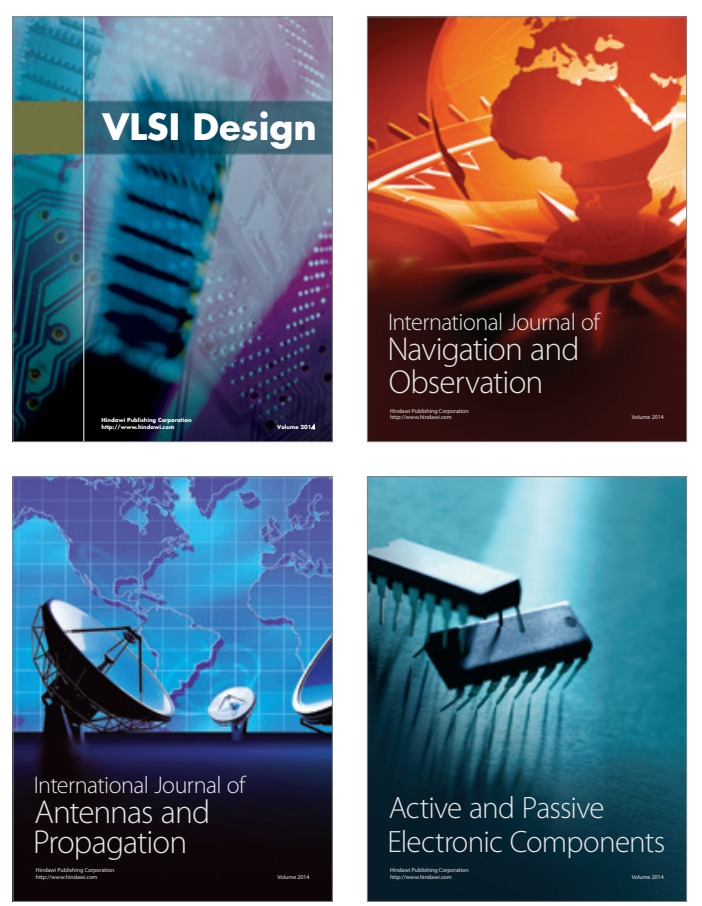
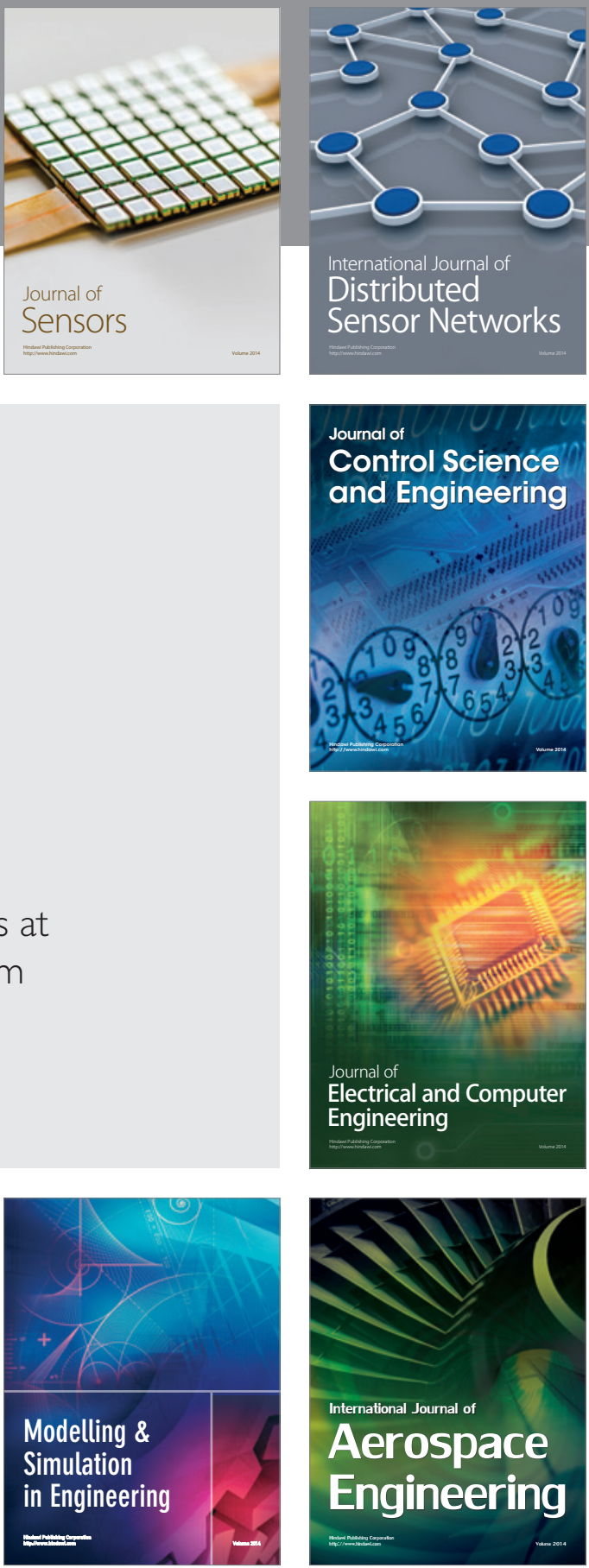

Journal of

Control Science

and Engineering
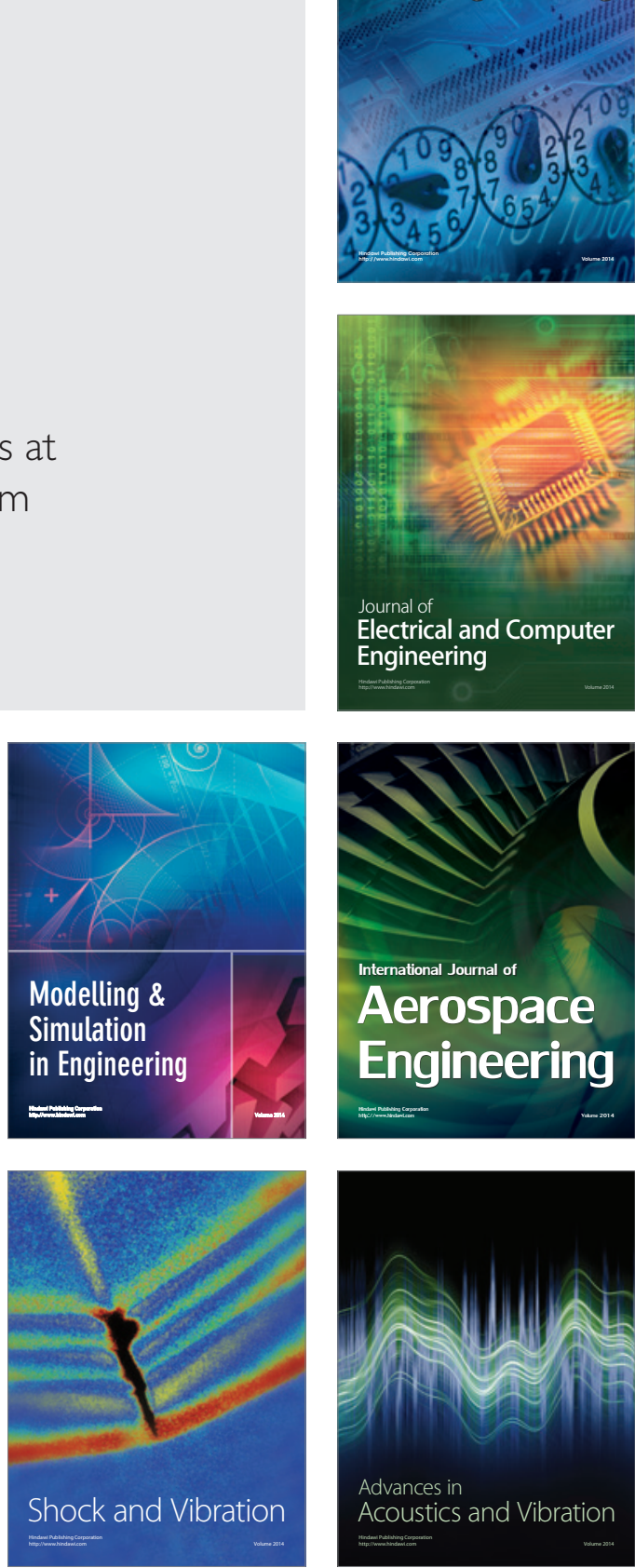